Japan. J. Med. Sci. Biol., 23, 199-210, 1970

\title{
IN VITRO CULTIVATION OF THE HETEROPHID TREMATODE, METAGONIMUS YOKOGAWAI, FROM THE METACERCARIA TO ADULT
}

\author{
KAZUO YASURAOKA AND KUnIKo KOJIMA \\ Department of Parasitology, National Institute of Health, \\ Shinagarva-ku, Tokyo 141, Japan
}

(Received: June 1st, 1970)

\begin{abstract}
SUMMARY : Eighty to $90 \%$ of the metacercariae of Metagonimus yokogawai excysted within 20 minutes in a trypsin solution after pretreatment with an acidfied pepsin solution. In a culture medium containing chick embryo extract, human serum and NCTC 109 in the ratio of $4: 3: 3$ at $37.5 \mathrm{C}$ with a gas phase of $8 \% \mathrm{CO}_{2}$ in air, gametogenesis took place, the seminal vesicle was packed with sperm, and sexual maturity finally attained, as evidenced by the appearance of 70 to 90 eggs in the uterus, but the vitellaria gave a poor Fast Red B positive reaction and the egg-shells were imperfectly formed. Addition of liver concentrate, yeast extract, a vitamin mixture, or hen-egg yolk to the medium has not given any more beneficial effects. It was found that cross fertilization may not be a necessary prerequisite to the egg-shell formation in the present species.
\end{abstract}

\section{INTRODUCTION}

The in vitro cultivation of helminth parasites has gradually attracted the attention of parasitologists. Successful in vitro cultivation of digenetic trematodes beginning with the metacercarial stage would provide a useful tool to solve many problems of trematode biology such as those of morphogenesis, metabolic requirement, immunity and host-parasite relationship. The present state of knowledge of the in vitro cultivation of metacercariae of digenetic trematodes has been ably described and reviewed by Silverman (1965), Smyth (1966), Clegg and Smyth (1966) and Taylor and Baker (1968). More recently, Berntzen and Macy (1969) grew excysted metacercariae of Sphaeridiotrema globulus to adults which produced eggs capable of embryonation, miracidium formation and hatching. The worms were grown at $42 \mathrm{C}$ in NCTC 109 with $20 \%$ egg yolk at pH 7.4 to 8.0 with a gas phase of $10 \% \mathrm{O}_{2}, 10 \% \mathrm{CO}_{2}, 80 \% \mathrm{~N}_{2}$. As far as is known, there are no published reports of the in vitro cultivation of the heterophid trematode from the metacercaria to the sexual maturity.

The first part of this paper describes a technique for obtaining large numbers of excysted metacercariae of Metagonimus yokogawai, while the main part deals with studies on the growth of the metacercaria in vitro. It is well known that this intestinal fluke is widespread in the central and southern Japan and pathogenic to man.

安羅岡一男・小島邦子 (国立予防衛生研究所寄生虫部) 


\section{Materials AND MethodS}

Natural infections of $M$. yokogawai metacercariae in the sweet fish " Ayu" in Japanese name), Plecoglossus altivelis, collected from the Takatsu River, Shimane Prefecture, Japan, were used for both in vivo and in vitro studies. The fishes were carried to the laboratory by air and maintained in covered shallow pans at $5 \mathrm{C}$ until they were used in the various experiments. The scales of the fishes were heavily infected sites, although cysts were found in the muscle. In vivo development of $M$. yokogawai was studied in female mice (gpc strain) weighing $16 \mathrm{~g}$ to $20 \mathrm{~g}$.

The method of excysting metacercariae for in vitro studies was as follows:

(1) Isolate the scales with cysts from fishes by means of a scalpel.

(2) Rinse thoroughly in $0.4 \%$ sterile sodium chloride.

(3) Treat with $0.7 \% \mathrm{HCl}-0.03 \%$ Difco Pepsin N.F. $(1: 3,000)$ for $3 \mathrm{hr}$ at 39 to $40 \mathrm{C}$.

(4) Rinse twice in $0.8 \%$ sterile sodium chloride.

(5) Treat with $20,000 \mathrm{Hb}$ units/ml trypsin diluent at $\mathrm{pH} 7.1$ (Mochida Pharmaceutical Manufacturing Co., Tokyo) for $30 \mathrm{~min}$ at $37 \mathrm{C}$.

After excystation in the trypsin diluent, the metacercariae were rinsed several times with Krebs-Ringer-" Tris" solution (Sommerville and Weinstein, 1967) containing $200 \mathrm{units} / \mathrm{ml}$ penicillin and $100 \mu \mathrm{g} / \mathrm{ml}$ of streptomycin. With all necessary aseptic precautions, the metacercariae were cultured in the different media in culture tubes ( 14 by $150 \mathrm{~mm}$ with Morton closure) or Carrel flasks ( $25 \mathrm{~mm}$ in diameter with Morton closure). The volume of medium used in each of these vessels was $2 \mathrm{ml}$ in which the number of metacercariae varied considerably but most cultures had between 50 and 100 . Both the culture tubes and flasks were placed in a $\mathrm{CO}_{2}$ incubator at $37.5 \mathrm{C}$ gassed with $8 \% \mathrm{CO}_{2}$ in air. The culture tubes were rotated in drums at 12 revolutions per hr, while the flasks were left static.

Cultures were examined at $24 \mathrm{hr}$ intervals under an inverted microscope, using $\times 40$ and $\times 100$ magnification. Specimens were removed at $48 \mathrm{hr}$ intervals, fixed in Carnoy's acetic-alcohol, stained with Heidenhein's iron hematoxylin and then counterstained either with methylene blue or eosin. Flukes removed daily from mice following their infection with $M$. yokogawai were stained by the same procedure.

The component of culture media used is given in Table 1 . Chick embryo extract (CEE) was prepared following the procedures described by Weinstein and Jones $(1956,1959)$. Human serum was obtained from a blood bank and was inactivated at $56 \mathrm{C}$ for $30 \mathrm{~min}$ before use. Liver concentrate (Sigma Chemical Co.) and yeast extract (Difco Co.) were made up as $1 \%$ and $0.5 \%$ aqueous solutions, respectively, and were sterilized using a $0.45 \mu$ Millipore filter. The composition and final concentration of the vitamin mixture was as follows: $25 \mathrm{mg}$ calcium pantothenate, riboflavin, thiamine hydrochloride; $30 \mathrm{mg}$ d-biotin, folic acid; $62.5 \mathrm{mg}$ niacin, niacinamide, pyridoxine hydrochloride, pyridoxal hydrochloride ; $125 \mathrm{mg}$ p-aminobenzoic acid, i-inositol; $1250 \mathrm{mg}$ choline chloride ; dissolved in $100 \mathrm{ml}$ glass distilled water. It was sterilized using a $0.45 \mu$ Millipore filter. NCTC 109 (Difco Co.) was obtained commercially. NCTC 109 with $50 \%$ hen-egg yolk (Y-109) was made up principally according to the procedure of Berntzen and 
Table 1. Component of culture media given in parts per $10 \mathrm{ml}$

\begin{tabular}{cccccccc}
\hline Medium & CEE 100 & $\begin{array}{c}\text { Human } \\
\text { serum }\end{array}$ & $\begin{array}{c}\text { Liver }^{1)} \\
\text { concentrate } \\
1 \%\end{array}$ & $\begin{array}{c}\text { Yeast } \\
\text { extract } \\
0.5 \%\end{array}$ & $\begin{array}{c}\text { Vitamin } \\
\text { mixture }\end{array}$ & Y-1094) & $\begin{array}{c}\text { NCTC } \\
109\end{array}$ \\
\hline A & - & - & - & - & - & - & 10 \\
B & - & 2 & - & - & - & - & 8 \\
C & 4 & 3 & - & - & - & - & 3 \\
D & 4 & 3 & 0.5 & - & - & - & 2.5 \\
E & 4 & 3 & - & 1 & - & - & 2 \\
F & 4 & 3 & 0.5 & - & 0.5 & - & 2 \\
G & 4 & 3 & 0.5 & 1 & - & - & 1.5 \\
H & 4 & 3 & - & - & - & 3 & - \\
I & - & - & - & - & - & 10 & - \\
\hline
\end{tabular}

1), 2), 3) and 4) Refer to the text.

Macy (1969). Penicillin and streptomycin in concentrations of 200 units and 100 $\mu \mathrm{g}$ per $\mathrm{ml}$ were added to all the media and $\mathrm{pH}$ adjusted to 7.2 with $5 \% \mathrm{NaHCO}_{3}$. The medium was replaced with fresh one every day or every other day with the usual precautions to avoid contamination.

\section{RESUlts}

\section{Excystment}

Although the majority of the metacercariae were released from the scales by the pepsin treatment, the metacercariae themselves appeared to be unaffected by the pepsin and the worm normally remained encysted. However, on transfer to the trypsin solution, the metacercaria commenced to rotate vigorously within the cyst. Within a few minutes a small elevation occurred at one point on the cyst wall, and after the next 5 to $10 \mathrm{~min}$ the forebody of the metacercaria burst through the wall where the elevation appeared. It was found that 80 to 90 per cent of the metacercariae excysted within $20 \mathrm{~min}$ in the trypsin solution. It is worth noticing that except in the vicinity of the excystment hole, the cyst wall appeared to be unaffected by the treatment.

\section{Development in Vitro in Comparison With that in Vivo}

Excysted metacercariae posses only primordia of the ovary and testes, the former lying symmetrically one another lateral to the excretory vesicle and the latter lying medio-anterior to the excretory vesicle. The excretory vesicle is flat and $\mathrm{V}$-shaped containing minute excretory granules (Fig. 5).

The metacercariae remained active for approximately 2-3 days in NCTC 109 (medium A) and by that time began to show considerable vacuolization and were all dead by day 4 , irrespective of whether the cultures were rotated. None ever showed any sign of development. However, the presence of serum substrate had a considerable effect on survival, e. g. NCTC 109 supplemented with $20 \%$ human serum (medium B) maintained metacercariae for as long as 25 to 30 days and exceptionally up to 35 days. Concomitant with the increased survival time the 
metacercariae showed limited growth and development. The excretory vesicle was constricted in the anterolateral owing to the growth of testes and resembled the letter "Y" in shape. The use of rotating tubes improved survival and seemed well suited for cultivation studies with $M$. yokogawai. In the following experiments, therefore, all cultures were established in roller tubes.

It was found that development up to the adult stage could be achieved in a culture medium containing CEE, human serum and NCTC 109 in the ratio of $4: 3: 3$ (medium C). Figure 1 shows the order and day of appearance for internal structure during the development of $M$. yokogawai in vivo and in vitro from the metacercaria to adult. These remarks are applied to those specimen which developed best, because wide variations in degree of development were observed in any one culture or host animal. As can be seen from days of appearance of the various organs and structures there is a considerable time lag in development of flukes grown in vitro as compared with that in vivo. It has taken an at least 2 to 3 times longer period for adult-stage flukes to develop in vitro than in vivo. Three sets of measurements of in vitro and in vivo grown flukes were made according to the way of Berntzen and Macy (1969): (1) relative body area (the product of maximum width of whole mounts multiplied by their length); (2) diameter of the ovary ; (3) diameter of the right testes. In all cultures there were a few flukes which had died or remained in the metacercarial stage irrespective of the occurrence of develop-

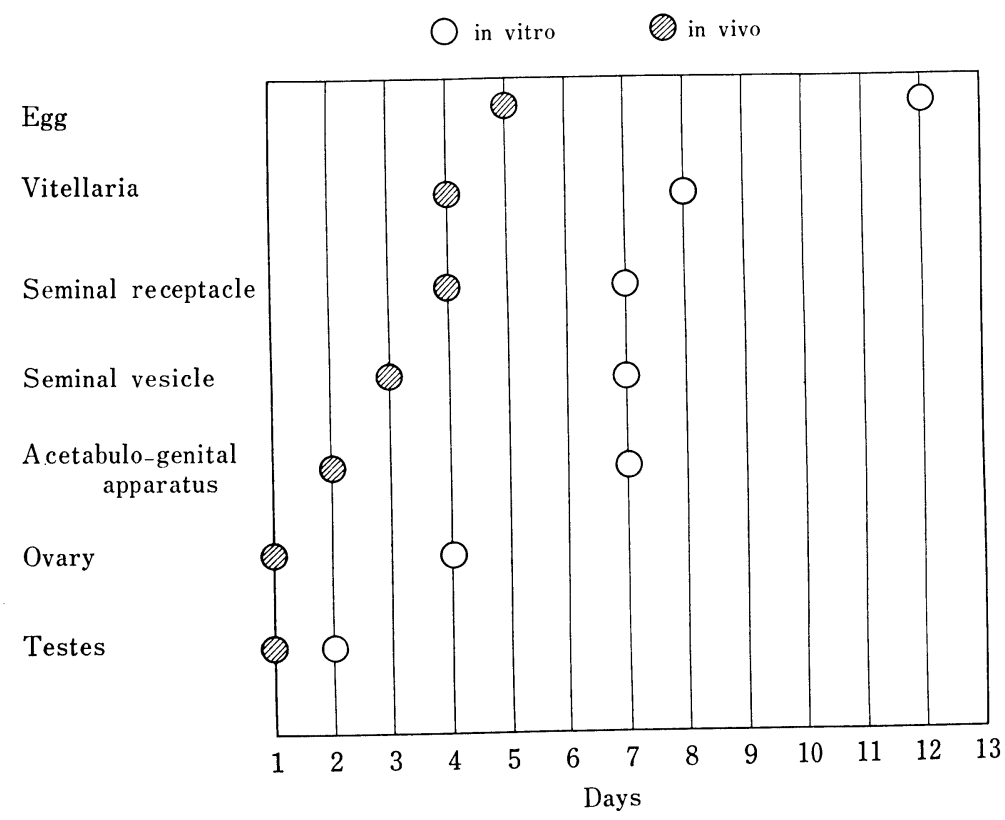

Fig. 1. Time of appearance of various organs in Metagonimus yokogawai grown in vivo and in vitro. Morphological development was determined on the stained whole mounts. In vitro flukes were grown in medium $\mathrm{C}$ with a gas phase of $8 \% \mathrm{CO}_{2}$ in air at $37.5 \mathrm{C}$. In vivo grown flukes were from mice. 
ment in the majority. The results were based on the best 10 flukes in a sample to eliminate variations in number of dead flukes in it.

Measurements of the relative body area as a function of time are shown in Figure 2. In vivo, flukes grew rapidly and attained their maximum size within 7 days. In vitro, the maximum size was reached after 16 days and the area was only two-thirds of the size of flukes grown in vivo. Figures 3 and 4 show measurements of the right testes and ovary size respectively. The delayed growth of these organs was similar to that of the relative body area.

In flukes grown in medium $\mathrm{C}$, gametogenesis took place, the seminal vesicle was packed with sperm, and sexual maturity finally attained, as evidenced by the appearance of 70 to 90 eggs in the uterus, but the vitellaria gave a poor Fast Red B positive reaction and the egg-shells were imperfectly formed (Figs. 6-8). The eggs were ovoidal in shape, light yellowish-brown in color, and measured $24.7(21.4-28.6) \mu$ by $12.8(10.7-14.3) \mu$ as contrasted with thoes from flukes grown in vivo which were $27.6(25.0-28.6) \mu$ by $14.3(11.4-16.1) \mu$; they contained

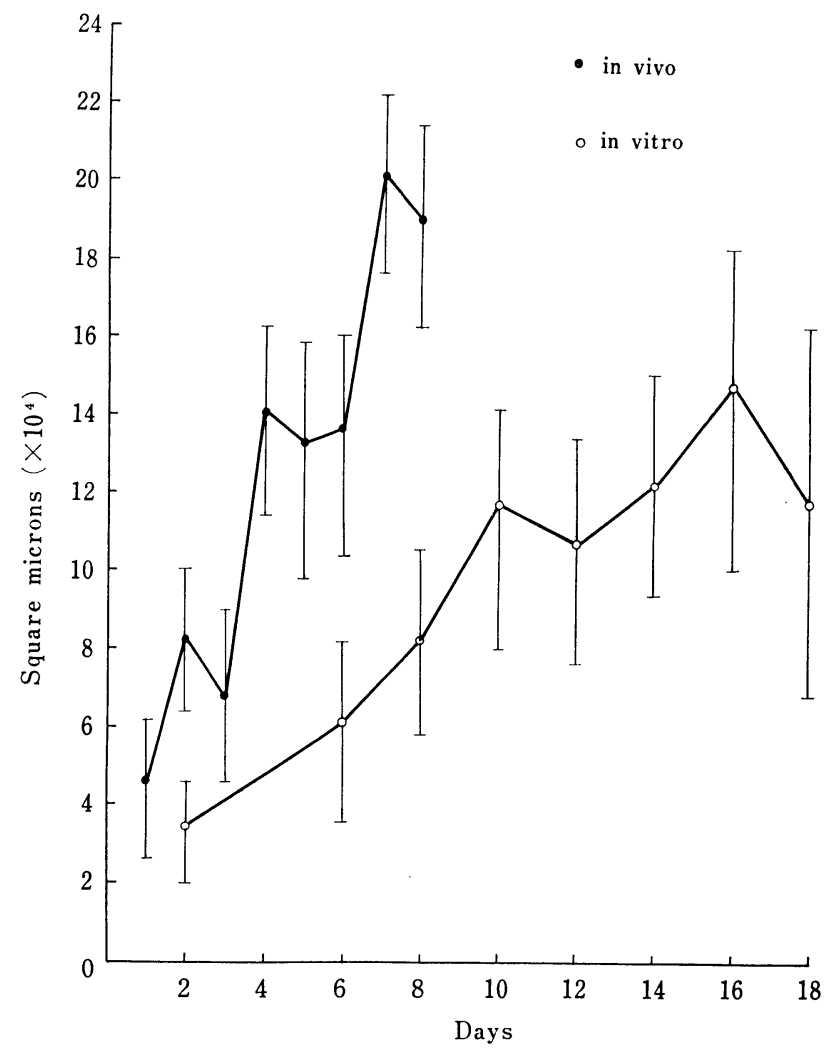

Fig. 2. Comparison of relative body area of $M$. yokogawai in vivo and in vitro for varying day periods. Each point represents the median of the best 10 flukes measured in a sample. Brackets are a $95 \%$ confidence limit from median area.

In vitro flukes were grown in medium $\mathrm{C}$ with a gas phase of $8 \%$ $\mathrm{CO}_{2}$ in air at $37.5 \mathrm{C}$. In vivo grown flukes were from mice. 
a large amount of hematoxylin positive substance (nucleic acids) but were lacking in their characteristic operculated shells. At the one end there was frequently a short comma-shaped extension of the shell (Fig. 9).

Addition of liver concentrate (media D, F and G), yeast extract (media $\mathrm{E}$ and $\mathrm{G}$ ), a vitamin mixture (medium $\mathrm{F}$ ) or hen-egg yolk (medium $\mathrm{H}$ ) did not give more beneficial effects on growth and development of the metacercariae over that obtained in medium $\mathrm{C}$.

\section{A Single Worm Infection of Mice with M. Yokogawai}

Although a few well-developed flukes which had contained significant amounts of sperm in the seminal vesicle were present in the same culture, normal eggs with shells were not formed by those specimens. This might reflect the fact that with such small numbers of well-developed flukes distributed in a relatively large volumes of culture media, the chance for one fluke to encounter another must be slim. It therefore appeared of interest to determine whether cross fertilization would be a necessary prerequisite to egg-shell formation in this species. On this assumption, 10 mice were fed each with a single metacercaria and autopsied 7 days after infection. The worms were recovered from 6 mices $(60 \%$ recovery). Significant amounts of egg-shell protein, sperm and apparently normal eggs with shells were present in all the specimens obtained (Fig. 10).

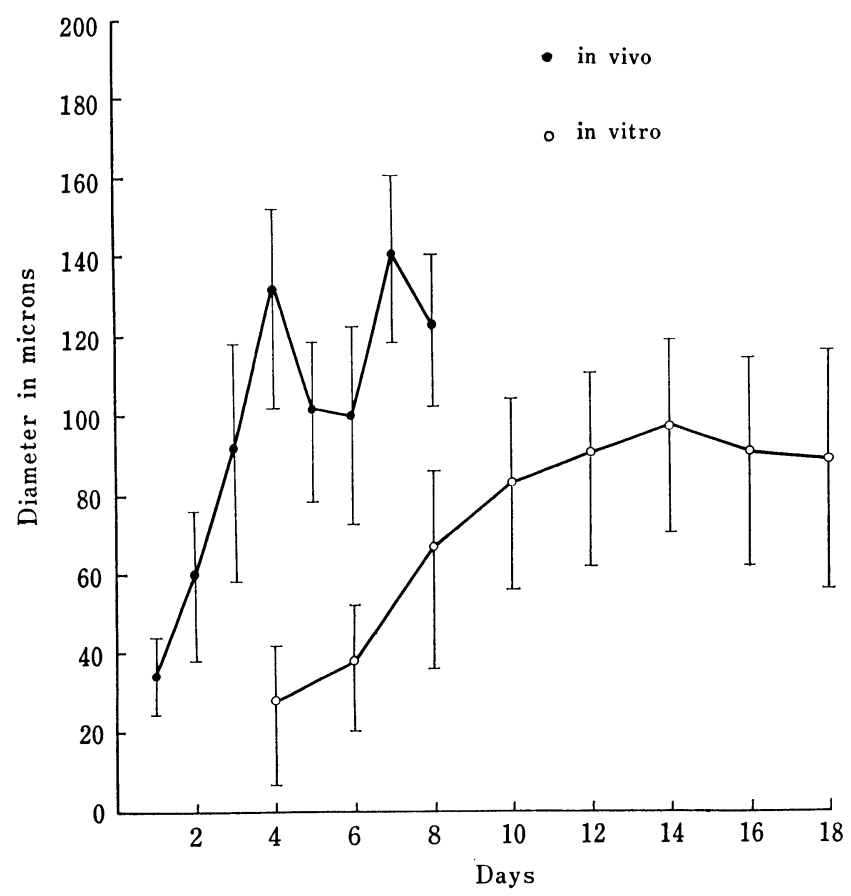

Fig. 3. Comparison of testes (right) size of M. yokogawai in vivo and in vitro for varying day periods. Other features are the same as in Fig. 2. 


\section{DISCUSSION}

The first step in the process of in vitro cultivation of $M$. yokogawai was the release of the juvenile flukes from the enclosing cyst wall. Observations on the in vitro excystment of trematode metacercariae have been made by a number of investigators. It has been shown that metacercariae require enzymes (pepsin or trypsin alone or in combination), bile or high concentrations of carbon dioxide. Kobayashi et al. (1959) reported that the metacercariae of $M$. yokogawai would not excyst in pepsin or pancreatin solutions alone, but required pig bile. The present experiment, however, indicated that pepsin in acid solution followed by trypsin in alkaline solution is essential for the excystment of $M$. yokogawai metacercariae. In the absence of trypsin the metacercariae will not enter the emergence phase.

In the present study, since attempts to excyst metacercariae were subsidiary to the subsequent in vitro cultivation, the methods and results did not give full details to make a critical assessment of excysting mechanism. If we can judge from our observations, excystment of $M$. yokogawai metacercariae may be an active process, as noted for other trematode species, Fasciola hepatica (Dixon, 1966) and Echinoparyphium serratum (Howell, 1968), because the cyst wall, except in the vicinity of the excystment hole, appeared to be unaffected by the enzyme treatment.

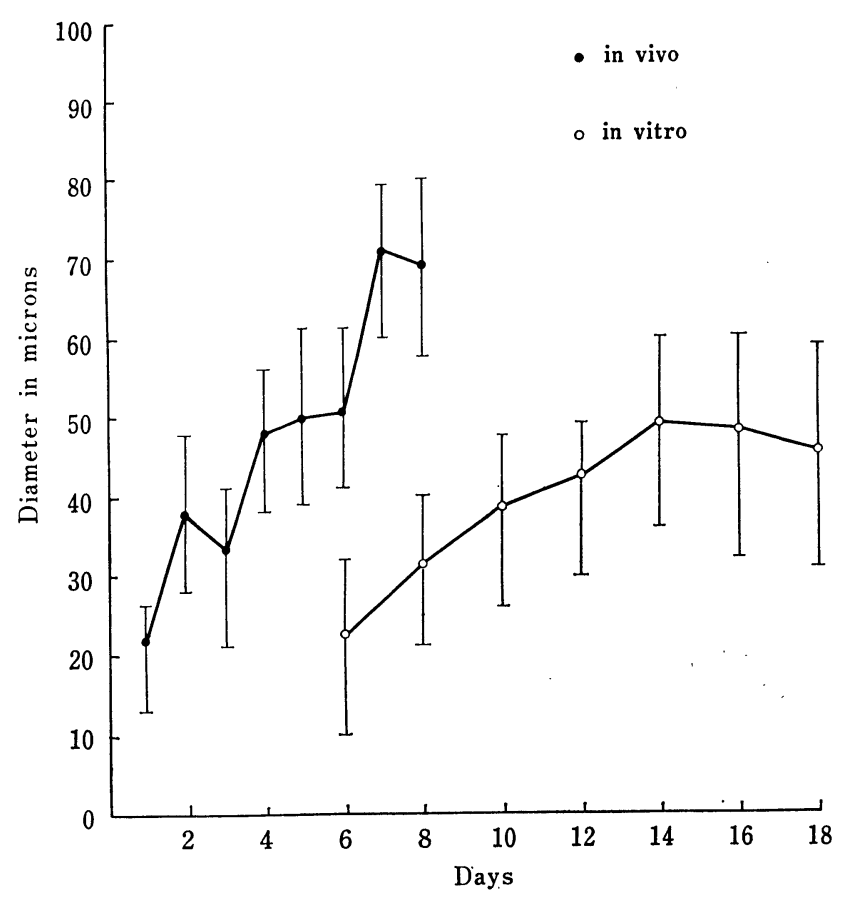

Fig. 4. Comparison of ovary size of M. yokogawai in vivo and in vitro for varying day periods. Other features are the same as in Fig. 2. 
In recent years, chemically defined media containing most of the amino acids, vitamins and other metabolites essential for the growth of several animal cell lines, such as medium 199, Eagle's medium and NCTC 109, have been frequently employed for the maintenance or cultivation of parasitic helminths in vitro. With the exception of unfavorable results with Taenia crassiceps (Taylor, 1963) and Schistosoma japonicum (Yasuraoka, 1970), the media have shown moderate success in both survival and limited egg production of helimths such as Schistosoma mansoni (Cheever and Weller, 1958 ; Senft and Senft, 1962 ; Jensen and Stirewalt, 1963), Clonorchis sinensis (Sun, 1969), Spirometra mansonoides (Mueller, 1959), Taenia crassiceps (Taylor, 1963) Dirofilaria immitis (Earl, 1959; Weinstein \& Sawyer 1961 ; von Brand et al., 1963), Litomosoides carinii (Taylor, 1960; Weinstein, 1963), Ascaris suum (Cleeland and Laurence, 1962 ; Levine and Silverman, 1969), Angiostrongylus cantonensis (Weinstein et al., 1963) and Philophthalmus sp. (Fried, 1962). The addition of various mammalian sera to the media has proved to enhance survival time of the worms and, in some cases, limited growth and development. In the present study $M$. yokogawai metacercariae survived for only 2-3 days in NCTC 109 alone without any change in internal structure or apparent growth. Whether the metacercariae were utilizing some of the constituent of NCTC 109 was not determined, since even saline maintained the metacercariae for the periods of 2 to 3 days. It would seem that reserves in the metacercaria are extremely limited.

Chick embryo extract was found to have a considerable growth promoting effect, when added to a medium consisting of NCTC 109 and human serum. In the absence of chick embryo extract, i. e. in medium B, the metacercariae survived for more than one month but showed only limited growth and development.

It is possible that serum derived from the natural host may prove to have a more salutary effect than that derived from other source. It has been well accepted that man is the most suitable host for $M$. yokogawai, since specimens of this fluke recovered from man are significantly well developed as compared with those from other mammals. For this reason, human serum was used as a substrate of cultures in the present study.

It was found that excysted metacercariae of $M$. yokogawai matured to the extent of producing motile sperm and abnormal eggs in a medium containing CEE, human serum and NCTC 109 in the ratio of $4: 3: 3$ (medium C) with a gas phase of $8 \% \mathrm{CO}_{2}$ in air. It should be stressed, however, that the size of the flukes which developed in the cultures was definitely smaller than that of worms recovered from mice, and there was a considerable time lag in development of flukes grown in vitro. Moreover, in contrast to development in vivo, the vitel-

Figures 5-10. (5) Excysted metacercaria prior to culture, $\times 120$. Fresh specimen. (6) Specimen after 17 days culture in medium $\mathrm{C}$ with a gas phase of $8 \% \mathrm{CO}_{2}$ in air at $37.5 \mathrm{C}, \times 120$. Hematoxylin-eosin stain. (7) Seminal vesicle filled with sperm. In vitro specimen after 17 days from the same culture as in Fig. 6. Hematoxylin-eosin stain, $\times 800$. (8) Testes with numerous stages of spermatogenesis. In vitro specimen after 17 days from the same culture as in Fig. 6 . Hematoxylin-eosin stain, $\times 800$. 

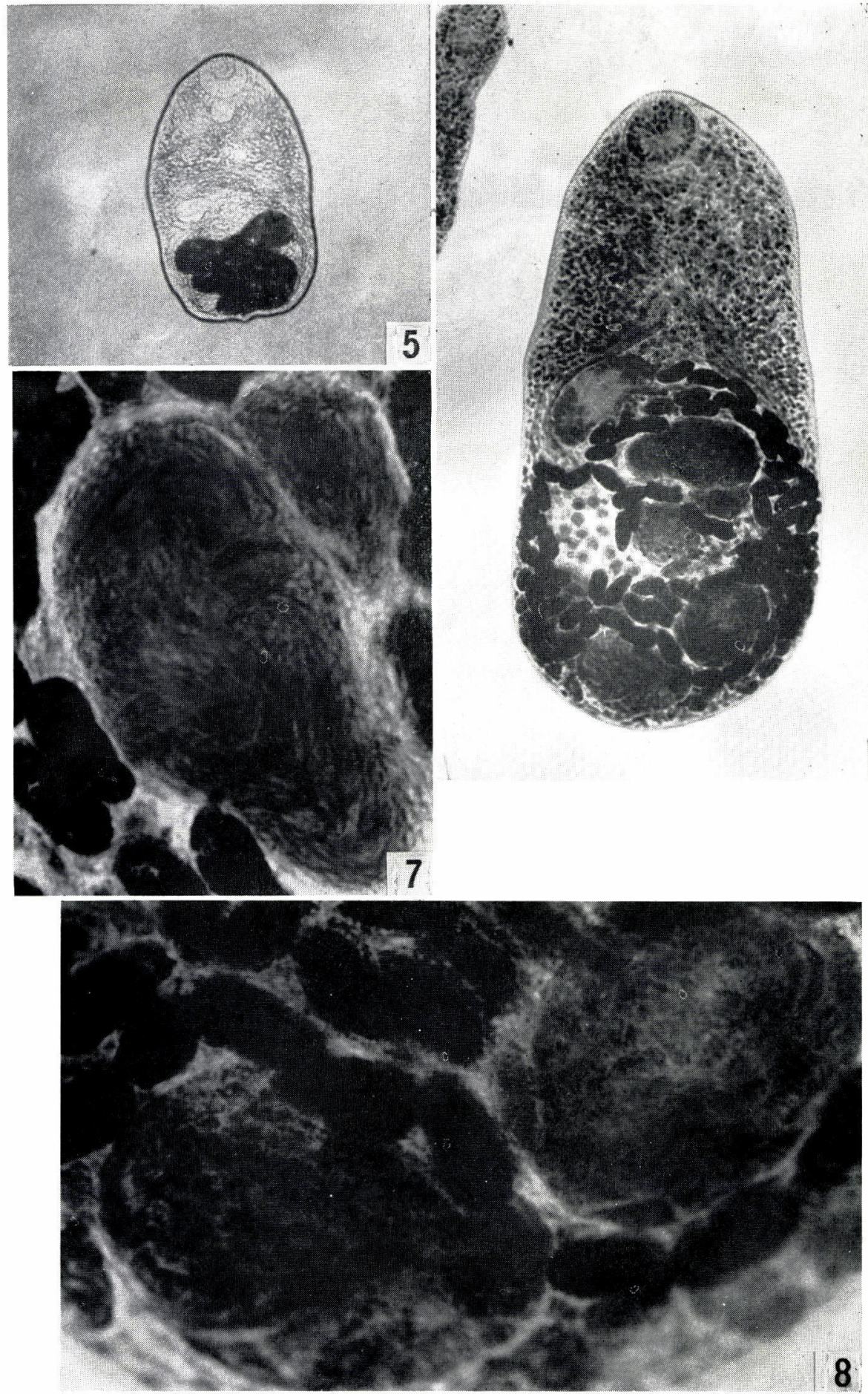

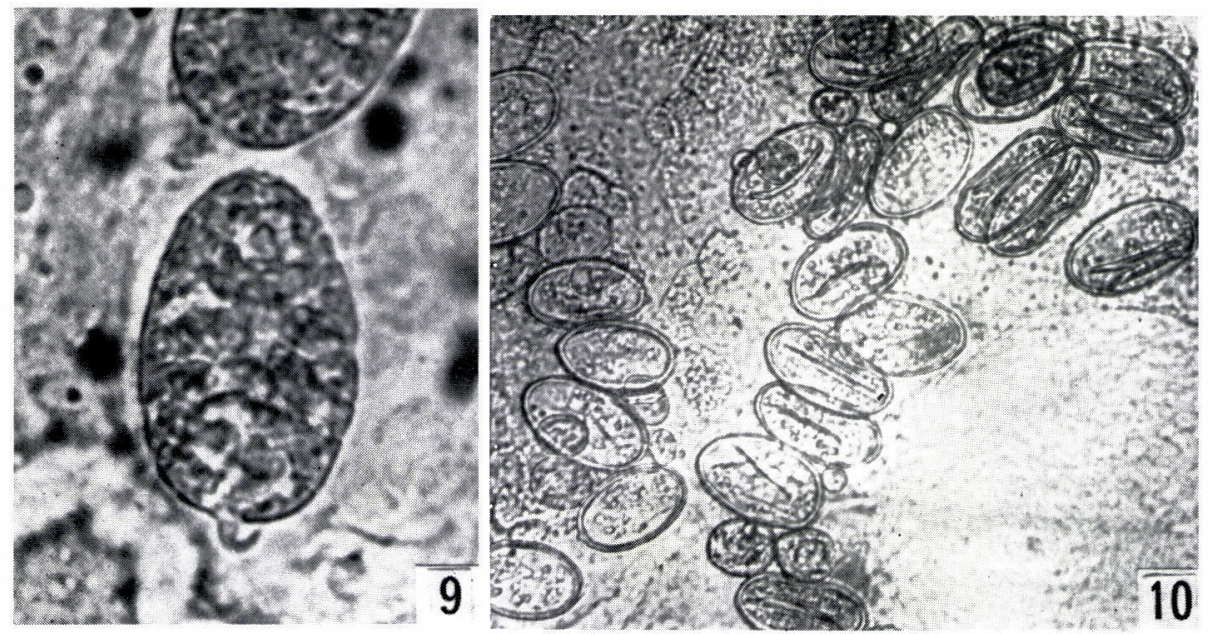

Figures 9-10. (9) Eggs in uterus. In vitro specimen after 15 days from the same culture as in Fig. 6. Note the comma-shaped extension of the shells, $\times 1400$. (10) Eggs in uterus of specimen from intestine of mice fed with a single metacercaria. After 7 days infection. Note apparently normal eggs with operculated shells. Fresh specimen, $\times 460$.

laria of the flukes grown in vitro gave a poor Fast Red $\mathrm{B}$ positive reaction and the formation of egg-shells was imperfect. Media containing hen-egg yolk used successfully by Berntzen and Macy in the culture of the digenetic trematode, Sphaeridiotrema globulus have been unsuccessful in promoting the vitellogenesis and egg-shell formation in the present species.

In some hermaphroditic digenetic trematodes it has been assumed that cross fertilization is necessary for the development of ovigerous worms. Fried (1962) found that mono-metacercarial infections with Philophthalmus hegeneri would not produce normal adults containing viable eggs. Similar results were obtained with Paragonimus kellicotti (Sogandares-Bernal, 1966), Japanese P. westermani (Yokogawa et al., 1960) and Zygocotyle lunata (Bocha, 1966). On the other hand, Beaver (1937) and Lie (1965) showed that cross fertilization is not necessary for the formation of fertile eggs in Echinostoma revolutum and E. malayanum, and the same was true with Philophthalmus megalurus (Nollen, 1968) and Taiwanese P. westermani (Fan and Chiang, 1970). It thus seems that the production of normal viable eggs requires cross fertilization in some species of digenetic trematodes but not in others. In the present study, it has shown that mono-metacercarial infections with $M$. yokogawai resulted in adult worms capable of producing normal eggs with shells and that cross fertilization may not be a necessary prerequisite to egg-shall formation in this species. Failue to obtain adult $M$. yokogawai which produces normal viable eggs in vitro may possibly be related to a nutritional problem and also to such an alternative enzyme system for the stabilization of egg-shall protein as suggested by Bell and Smyth (1958), although these are not resolved as yet. 


\section{ACKNOWLEDGEMENTS}

The authors are indebted to Dr. Tatsushi Ishizaki, Chief of Department of Parasitology of this Institute, for his valuable discussions. Thanks are also due to Dr. Tsutomu Koyama, Miss Yoko Takemura and Miss Masako Fujiwara for their sincere technical assistance during this research project.

\section{REFERENCES}

BACHA, W. J. (1966): Viable egg production in Zygocotyle lunata following monometacercarial infection. J. Parasit., 52, 1216-1217.

BEAVER, P. C. (1937): Experimental studies on Echinostoma revolutum (Froelich) a fluke from birds and mammals. Ill. Biol. Monog. 15, 1-96.

BELl, E. G. AND SMYTH, J. D. (1958): Cytological and histochemical criteria for evaluating development of trematodes and pseudophyllidean cestodes in vivo and in vitro. Parasitology, 48, 131-148.

Berntzen, A. K. AND MACY, R. W. (1969): In vitro cultivation of the digenetic trematode Sphaeridiotrema globulus (Rudolphi) from the metacercarial stage to egg production. J. Parasit., 55, 136-139.

Cheever, A. W. AND Weller, T. H. (1958): Observations on the growth and nutritional requirements of Schistosoma mansoni in vitro. Amer. J. Hyg., 68, 322.

Cleeland, R. AND LAURence, K. A. (1962): In vitro cultivation of Ascaris lumbricoides var. suum larvae. J. Parasit., 48, 35.

ClegG, J. A. AND Smyth, J. D. (1966): Growth, development and culture methods: parasitic plathelminthes. Chemical Zoology, Vol. 1, Chapter 1. Academic Press, London and New York.

Dixon, K. E. (1966): The physiology of excystment of the metacercaria of Fasciola hepatica L. Parasitology, 56, 431-456.

EARL, P. R. (1959): Filariae from the dog in vitro. Ann. N. Y. Acad. Sci. 77, 163.

FAN, P. C. AND ChIANG, C. H. (1970): Exposure of kittens and puppies to single metacercariae of Paragonimus westermani from Taiwan, J. Parasit., 56, 48-54.

FrIED, B. (1962): In vitro studies on Philophthalmus sp., an ocular trematode. J. Parasit., $48,510$.

Howell, M. J. (1968): Excystment and in vitro cultivation of Echinoparyphium serratum. Parasitology, 58, 583-597.

Jensen, D. V. AND Stirewalt, M. A. (1963): Development of cercariae of Schistosoma mansoni under dialysis membranes in Rose multipurpose chambers. J. Parasit., 49 (5, Sect. 2, Suppl.): 61 .

Kobayashi, A., Iida, M., Hatano, N. Yamakawa, S., OKuno, K., Takahashi, T., HotTA, K. AND OCHI, M. (1959): Studies on excystation of the metacercaria of Metagonimus yokogawai, Acta Sch. Med. Gifu, 7, 822-828. (text in Japanese)

Levine, H. S. ANd Silverman, P. H. (1969): Cultivation of Ascaris suum larvae in supplemented and unsupplemented chemically defined media. J. Parasit., 55, 17-21.

LIE, K. J. (1965): Studies on Echinostomatidae (Trematoda) in Malaya. IX. The Mehlis' gland complex in echinostomes. J. Parasit., 51, 789-792.

Mueller, J. F. (1959): The laboratory propagation of Spirometra mansonoides (Mueller, 1955) as an experimental tool. III. In vitro cultivation of the plerocercoid larva in a cell-free medium. J. Parasit., 45, 561-573.

Nollen, P. M. (1968): Autoradiographic studies on reproduction in Philophthalmus megalurus (Cort, 1914) (Trematoda). J. Parasit., 54, 43-48.

SENFT, A. W. AND SENFT, D. G. (1962): A chemically defined medium for maintenance 
of Schistosoma mansoni. J. Parasit., 48, 551-554.

Silverman, P. H. (1965): In vitro cultivation procedures for parasitic helminths. Advances in Parasitology, Vol. 3, pp. 159-222. Academic Press, London and New York.

Sмyтн, J. D. (1966): The physiology of trematodes. W. H. Freeman and Co., San Francisco, p. 256.

SOGANDARES-BERNAL, F. (1966): Studies on American paragonimiasis. IV. Observations on the pairing of adult worms in laboratory infections of domestic cats. J. Parasit., 52, 701-703.

Sommerville, R. I. AND Weinstein, P. P. (1967): The in vitro cultivation of Nippostrongylus brasiliensis from the late fourth stage. J. Parasit., 53, 116-125.

Sun, T. (1969): Maintenance of adult Clonorchis sinensis in vitro. Ann. Trop. Med. \& Parasit., 63, 399-402.

TAYLOR, A. E. R. (1960): Maintenance of filarial worms in vitro. Exptl. Parasit., 9, 113-120.

TAYLOR, A. E. R. (1963): Maintenance of larval Taenia crassiceps (Cestoda: Cyclophyllidea) in a chemically defined medium. Exptl. Parasit., 14, 304-310.

TAYLOR, A. E. R. AND BAKER, J. R. (1968): The cultivation of parasites in vitro. Blackwell Scientific Publications, Oxford and Edinburgh, p. 377.

von Brand, T., Bowman, I. B. R., Weinstein, P. P. And SAwyer, T. K. (1963): Observation on the metabolism of Dirofilaria uniformis. Exptl. Parasit., 13, 128-133.

WeINSTEIN, P. P. (1963): Development in vitro of the microfilariae of Wuchereria bancrofti and of Litomosoides carinii as far as the sausage form. Trans. Roy. Soc. Trop. Med. Hyg., $57,236$.

Weinstein, P. P. AND Jones, M. F. (1956): The in vitro cultivation of Nippostrongylus muris to the adult stage. J. Parasit., 42, 215-236.

Weinstein, P. P. AND JONES, M. F. (1959): Development in vitro of some parasitic nematodes of vertebrates. Ann. N. Y. Acad. Sci., 77, 137-162.

Weinstein, P. P., Rosen, L., Lacqueur, G. L. And Sawyer, T. K. (1963): Angiostrongylus cantonensis infection in rats and rhesus monkys and observations on the survival of the parasite in vitro. Amer. J. Trop. Med. Hyg., 12, 358-377.

Weinstein, P. P. AND SAwYeR, T. K. (1961): Survival of adults of Dirofilaria uniformis in vitro and their production of microfilariae. J. Parasit., 47 (4. Sect. 2, Suppl.),23.

YASURAOKA, K. (1970): Studies of methods of maintaining Schistosoma japonicum in vitro. (in press).

YoKogAwa, M., Yoshimura, H. AND Oshima, T. (1960): Studies on the experimental infection of dogs with a single metacercaria of $P$. westermani. Japan. J. Parasit., 9, 636-640. (text in Japanese with English summary). 